$$
\text { تأثير المجال الكهرومغناطيسي والاشعة فوق البنفسجية في انتاجية ثلاثة هجن }
$$

\title{
Effect of electromagnetic and Ultra Violate rays on production of Cucumis sativus $\mathrm{L}$.
}

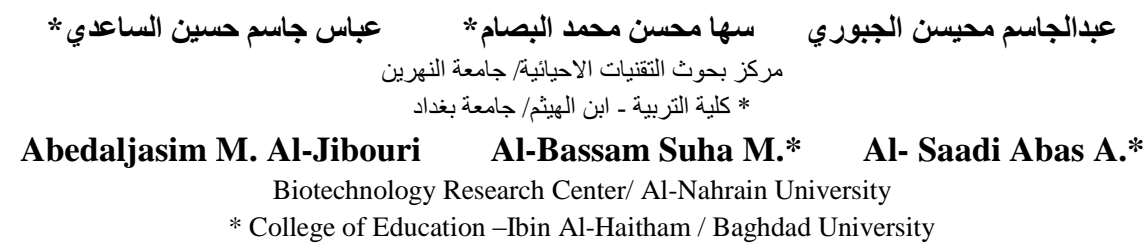

اخذت بذور ثلاث هجن من الخيار الامريكي الفي (Cucumis sativus L.) cucumber) وهي Lot Number (EM285 ورمز له بالرقم من Hybrid super green F1،1 ورمز له بالرقم 2 و F1 Hybrid Top CAEEN

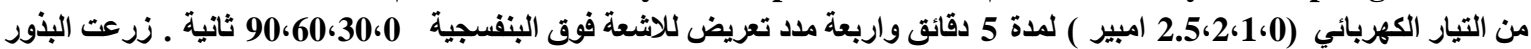

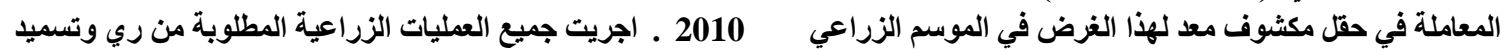

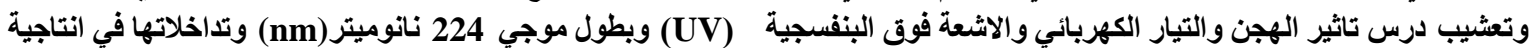

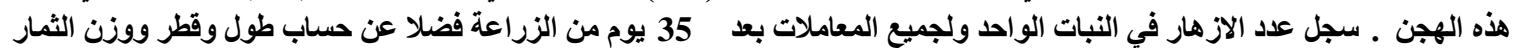

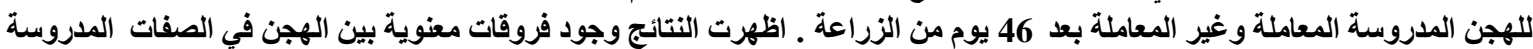

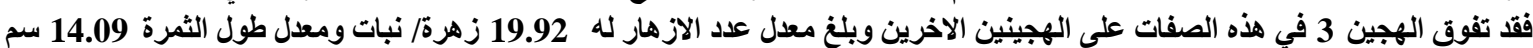

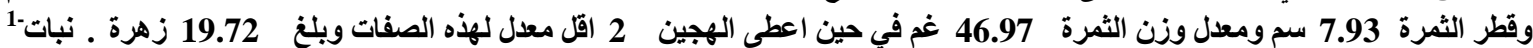

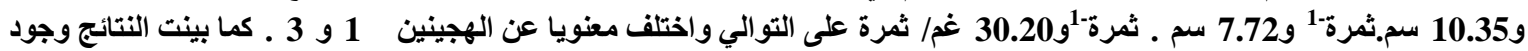

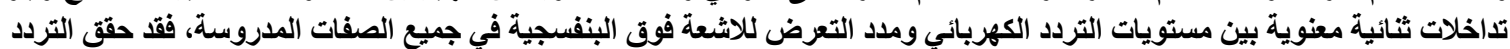

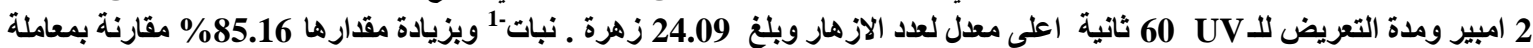

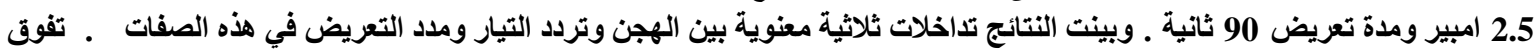

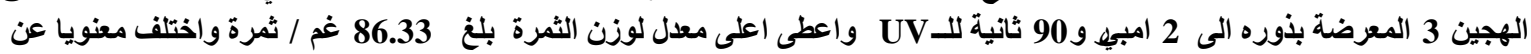
جميع التداخلات .

Abstract

Three American cucumber (Cucumis sativus L.) hybrids namely Lot Number (EM 285), labeled number 1, Hybrid super Green F1, labeled number 2 and Hybrid Top CAEEN F1, labeled number 3 were studied. Seeds of these hybrids were exposed to four frequencies of electric current $(0,1,2,2.5)$ amber(Am.) for 5 minutes and four periods of exposure for ultra-violate rays (UV) at 224 nanometer $(\mathrm{nm})$ for $(0,30,60$ and 90$)$ second. The treated seeds were sown on 2010 in open field that prepared and fertilized. The effect of electronic current Am and UV on the production of these hybrids was studied. Flowers number/ plant were recorded after 35 days of sowing; length, radius and weight of fruit were recorded after 46 days of sowing. Results showed significant differences between the hybrids in the studied parameters. Hybrid 3 showed a significant increase compared with hybrids 1 and 2 since it gave the highest number of flowers (19.97 flowers. Plant $\left.{ }^{-1}\right)$, tallest fruit length and radius of fruit (14.09 and $7.93 \mathrm{~cm}^{-f_{r u i t}}{ }^{-1}$ respectively) and highest fruit weight 46.97 gm.fruit $^{-1}$. While hybrid 2 gave 16.72

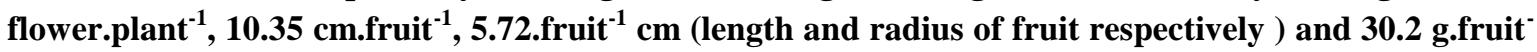
${ }^{1}$.The results also indicated a significant interaction between electric current and $\mathrm{UV}$ in all studied parameters. The $2 \mathrm{Am}$ frequency and $60 \mathrm{sec}$ of $\mathrm{UV}$ exposure gave highest flowers number (24.09 flower. plant ${ }^{-1}$ ) with an increase $85.16 \%$ compared with $2.5 \mathrm{Am}$ frequency and 90 sec. of $\mathrm{UV}$ exposure. The results also showed a significant interaction between hybrids, electric current and UV. Hybrid 3 treated with $2 \mathrm{Am}$ and 60 sec exposure gave highest fruit weight $86.33 \mathrm{gm}$.fruit ${ }^{-1}$ with a significant increase for all tri- interactions.

Key words: electromagnetic, Ultra Violate

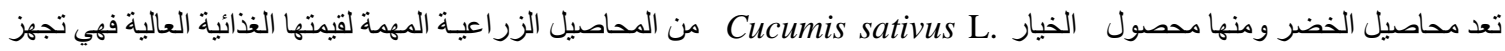

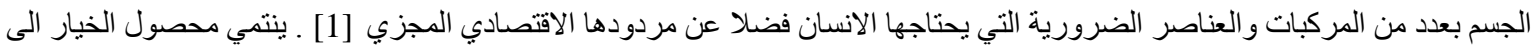




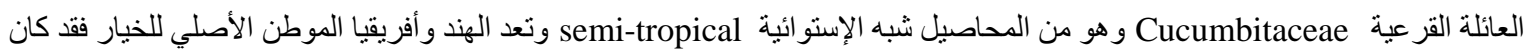

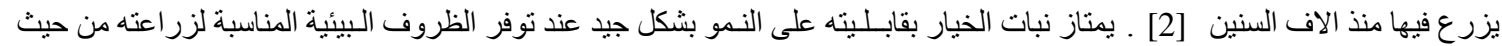

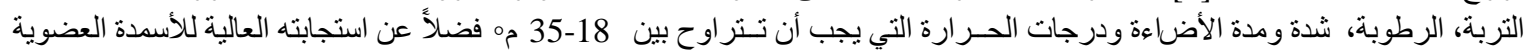

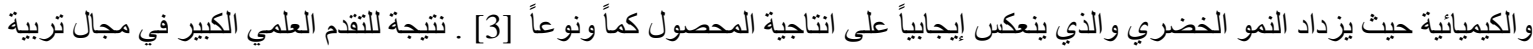

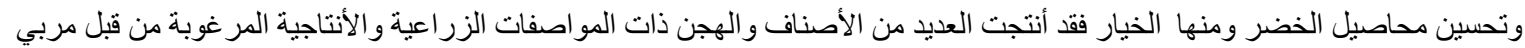

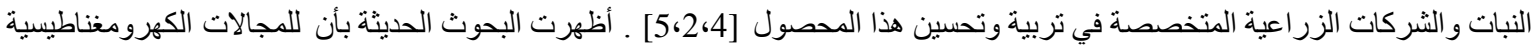

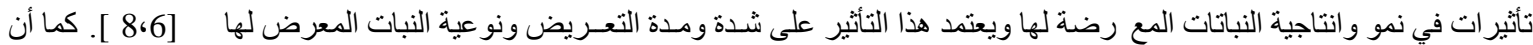

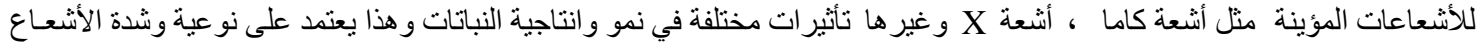

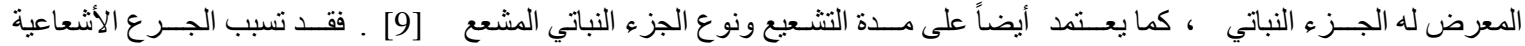

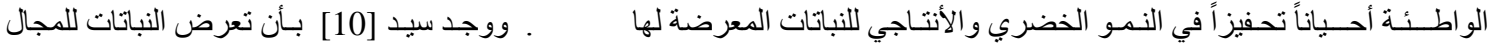

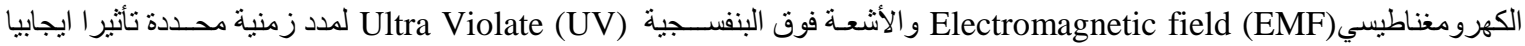

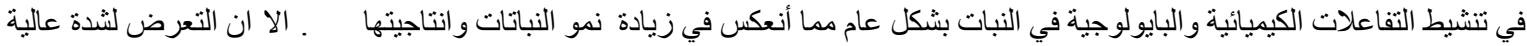

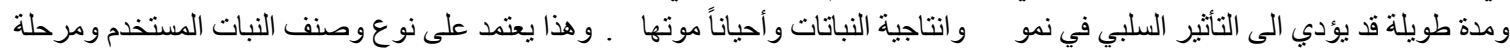

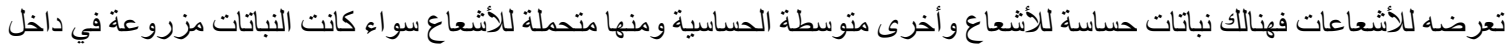

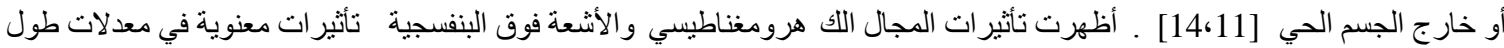

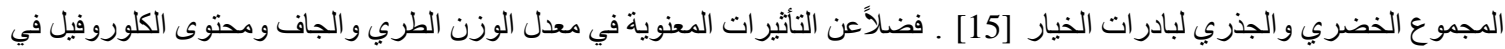

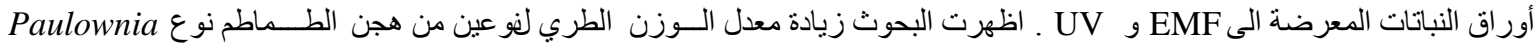

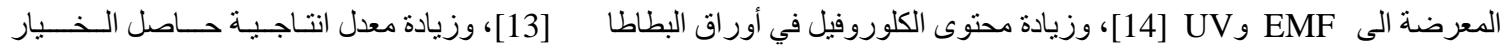

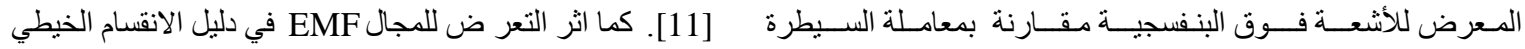
و وذذا ما أكده [16 Mitotic index (MI)

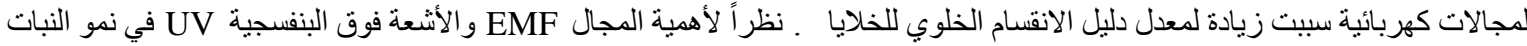

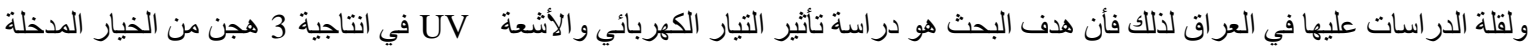
الى العراق

المواد وطرائق العمل العل

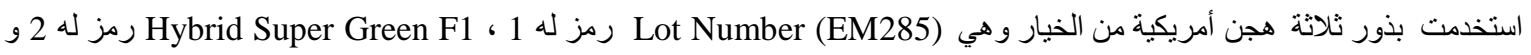
Hybrid Top CAEEN F1

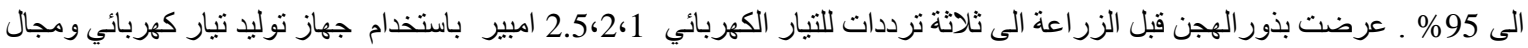

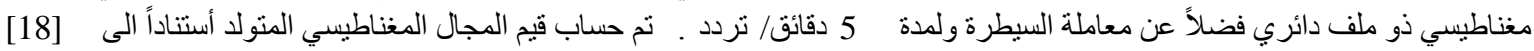

\section{B $=$ - NMoI}

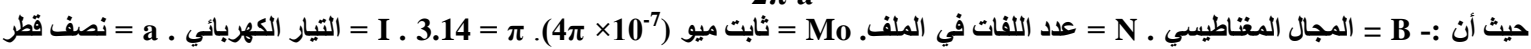
وحسب المعادلة التالية :- ملفئري علما بان عدد لفات الملف 850 لفة ، شدة التيار الكهربائي (2.5,2,1) أمبير وقطر الملف 6 سم وبذلك فقد كانت شدة المجال المغناطيسي هي : 1416.66×10 $110^{-7}, 133.33 \times 10^{-7}, 566.66 \times 10^{-7}$

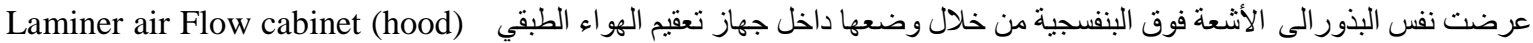

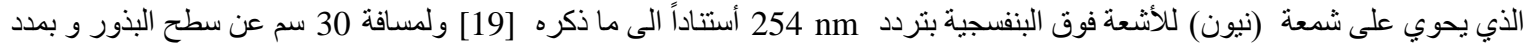

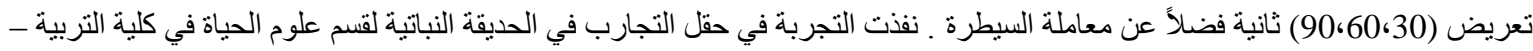

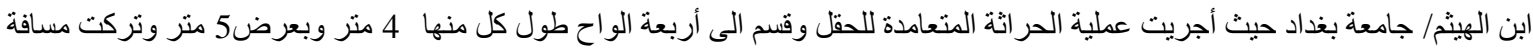

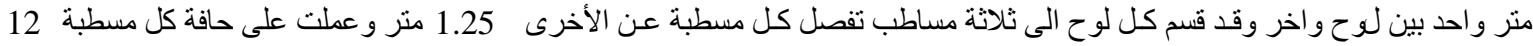

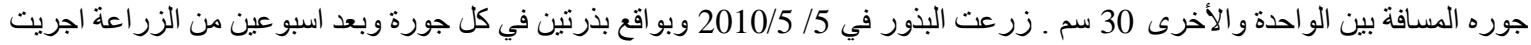

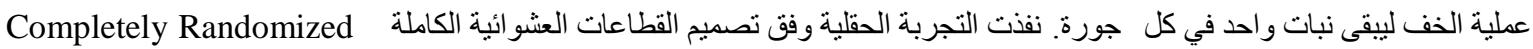
كتجربة عاملية بثلاثة مكررات (C) Block Design (CRBD)

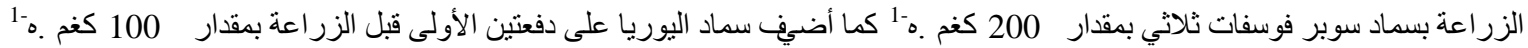

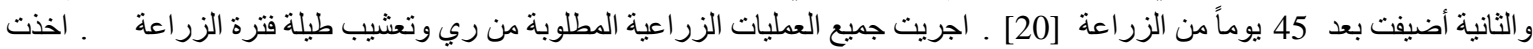

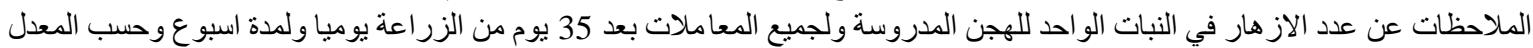

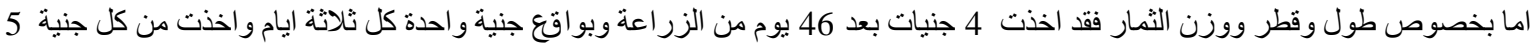

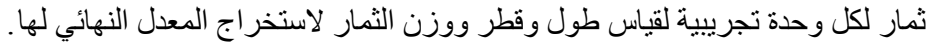

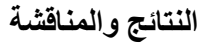
عدد الأزهار (زهرة.نبات -1)

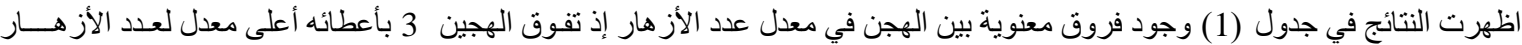

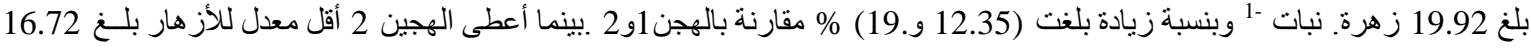




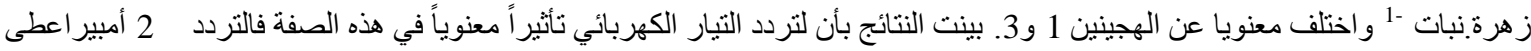

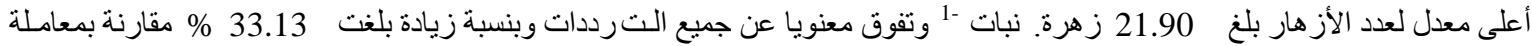

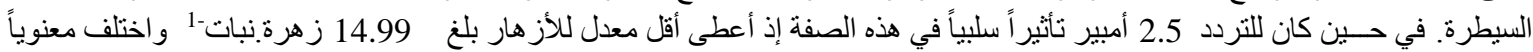

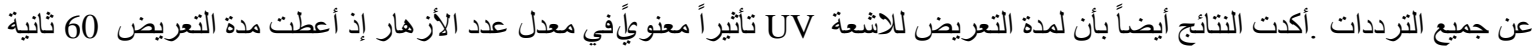

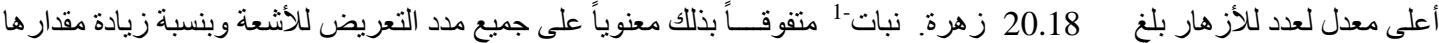

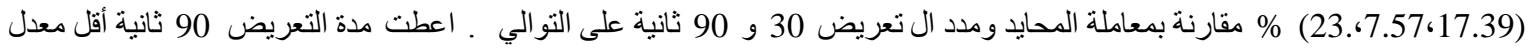

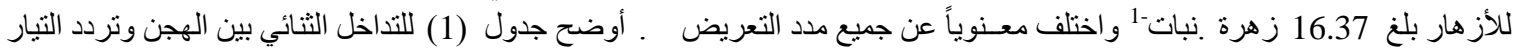

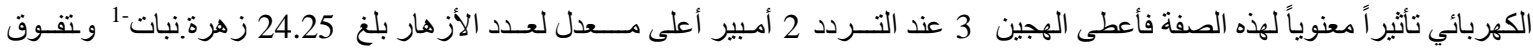
معـنويا على جميع التداخلات الأخرى و بنسبة زيادة بلغت

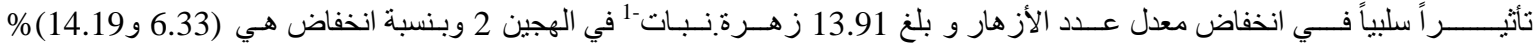

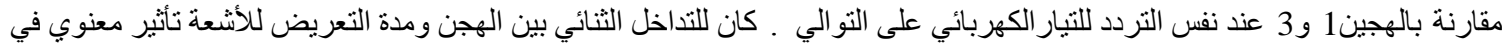

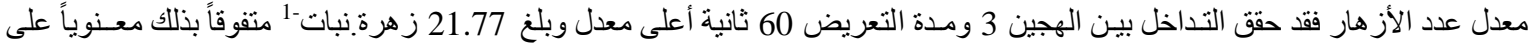

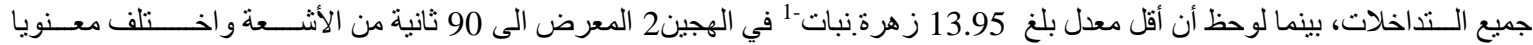

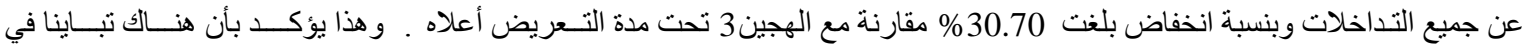

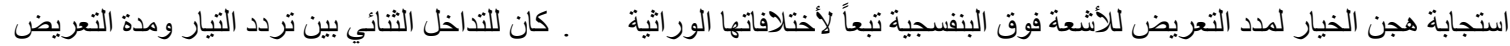
للأشعة تأثير معنوي لهذه الصفة فقد أعطى ال

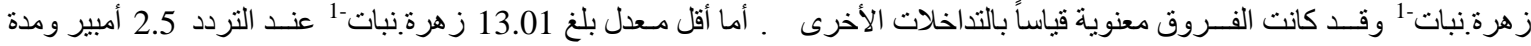

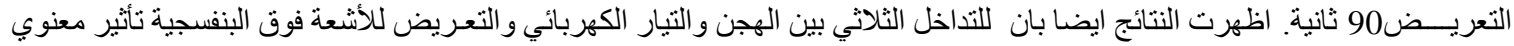

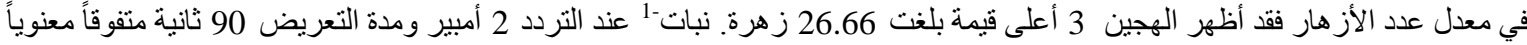

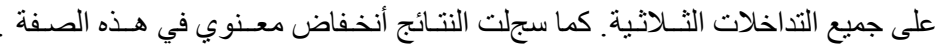
جدول (1): تأثير الهجن وتردد التيار الكهربائي ومدة التعريض للأشعة فوق البنفسجية في عدد الأزهار في النبات(زهرة .نبات-1 ).

\begin{tabular}{|c|c|c|c|c|c|c|}
\hline \multirow{2}{*}{ 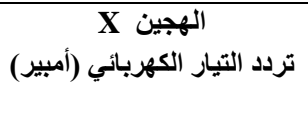 } & \multicolumn{4}{|c|}{ مدة التعريض للأشعة (ثانية) } & \multirow{2}{*}{ تردد التيار } & \multirow[b]{2}{*}{ الهجين } \\
\hline & 90 & 60 & 30 & $\mathbf{0}$ & & \\
\hline 16.46 & 13.93 & 18.50 & 17.66 & 15.75 & 0 & \\
\hline 18.40 & 15.83 & 20.36 & 19.26 & 18.16 & 1 & \\
\hline 21.20 & 17.66 & 24.00 & 22.83 & 20.33 & 2 & 1 \\
\hline 14.85 & 12.67 & 16.66 & 15.50 & 14.60 & 2.5 & \\
\hline 15.41 & 12.83 & $\mathbf{1 7 . 5 0}$ & 16.00 & 15.33 & $\mathbf{0}$ & \\
\hline 17.33 & 14.16 & 19.66 & 18.00 & 17.50 & 1 & \\
\hline 20.24 & 17.00 & 22.66 & 21.83 & 19.50 & 2 & 2 \\
\hline 13.91 & 11.83 & 15.77 & 14.56 & 13.50 & 2.5 & \\
\hline 17.49 & 14.83 & 20.16 & 18.50 & 16.50 & $\mathbf{0}$ & \\
\hline 21.73 & 24.50 & 22.83 & 20.66 & 18.95 & 1 & \\
\hline 24.25 & 26.66 & 25.61 & 23.99 & 20.76 & 2 & 3 \\
\hline 16.21 & 14.54 & 18.50 & 16.33 & 15.50 & 2.5 & \\
\hline 0.516 & \multicolumn{4}{|c|}{1.032} & \multicolumn{2}{|r|}{ L.S.D ( 0.05) } \\
\hline \multicolumn{7}{|l|}{ الهجين } \\
\hline 17.73 & 15.02 & 19.88 & 18.81 & 17.21 & 1 & الهجين X \\
\hline 16.72 & 13.95 & 18.89 & 17.59 & 16.45 & 2 & مدة التعريض \\
\hline 19.92 & 20.13 & 21.77 & 19.87 & 17.92 & 3 & للأثعة (ثانية) \\
\hline 0.258 & \multicolumn{4}{|c|}{0.516} & \multicolumn{2}{|r|}{ L.S.D (0.05) } \\
\hline \multicolumn{7}{|l|}{ تردد التيار الكهربائي (أمبير) } \\
\hline 16.45 & 13.86 & 18.72 & 17.38 & 15.86 & $\mathbf{0}$ & تردد التيار الكهربائي أمبير X \\
\hline 19.15 & 18.16 & 20.95 & 19.30 & 18.20 & 1 & مدة لتعريض \\
\hline 21.90 & 20.44 & 24.09 & 22.88 & 20.19 & 2 & للأشعة (ثانية) \\
\hline 14.99 & 13.01 & 16.97 & 15.46 & 14.53 & 2.5 & \\
\hline 0.298 & \multicolumn{4}{|c|}{0.596} & \multirow{2}{*}{\multicolumn{2}{|c|}{$\begin{array}{c}\text { L.S.D (0.05) مدة التعريض للأشعة (ثانية) } \\
\text { S.D(0.05) }\end{array}$}} \\
\hline & 16.37 & 20.18 & 18.76 & 17.19 & & \\
\hline
\end{tabular}

وبلغ 11.83 زهرة.نبات-1 في الهجين 2 تحت التردد 2.5 أمبير ومدة التعريض 90 نانية واختلف معنويا عن معاملة السيطرة للهجين أعلاه والتي بلغت 15.33 زهرة.نبات 11.83 زهن. 
أوضحت النتائج أن التاثير الايجابي لكل من التيار الكهربائي والتعريض للأشعة فوق البنفجية في معدل عدد الأزهار قد يعود الى تاثير هما

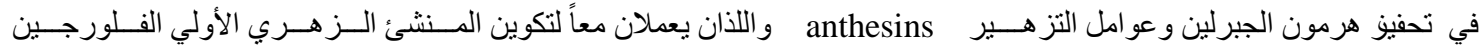

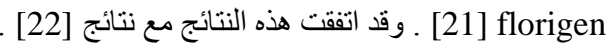

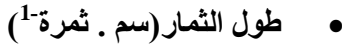

تشير النتائج في جدول (2) وجود تأثثير معنوي للهجين في معدل طول الثمار إذ تفوق معنوياً الهجين 3 بأعطائه أعلى معدل للطول بلغ

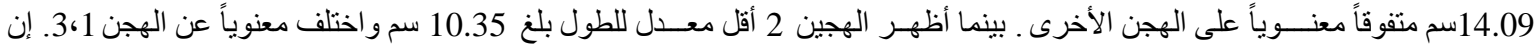

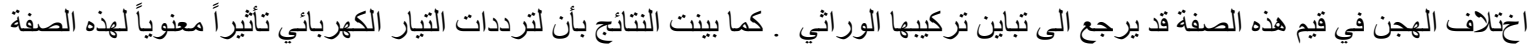

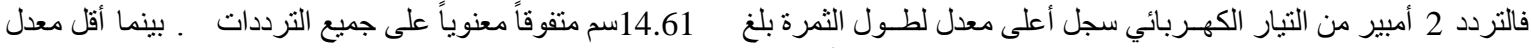
للطول سجل عند التردد 2.5 أمبير وبلغ 9.67 سم واختلف معنوياً عن جميع الترددات الأخرى وبنسبة انخفاض

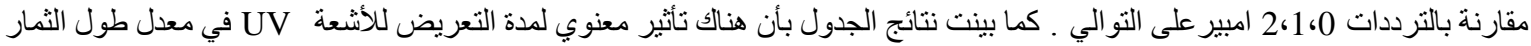

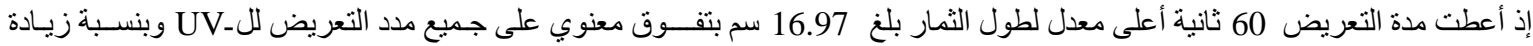

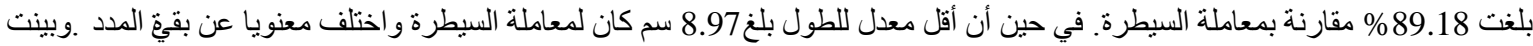

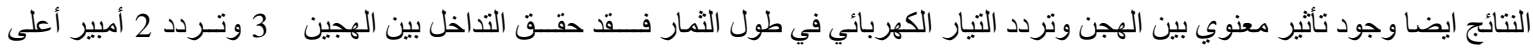

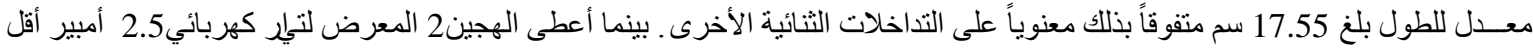

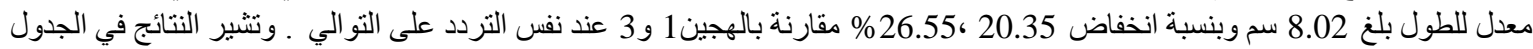

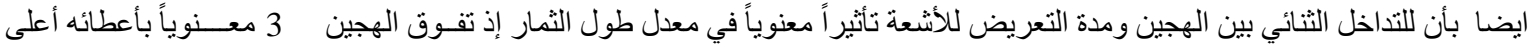

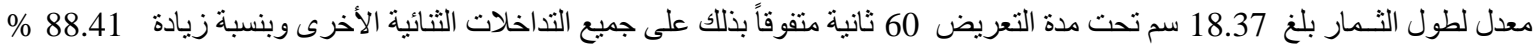

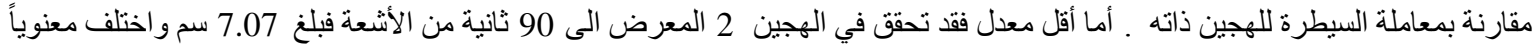
عن جميع التداخلات ـ و أظهرت نتائج الجدول أيضاً وجود ناثثر معنوي للتداخل بين تردد التيار الكهربائي ومدة التشعيع بأشعة

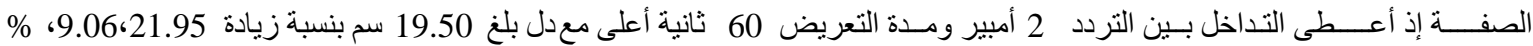

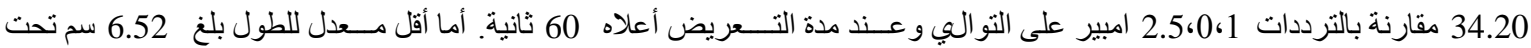

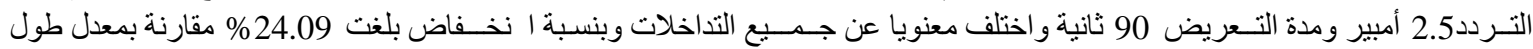

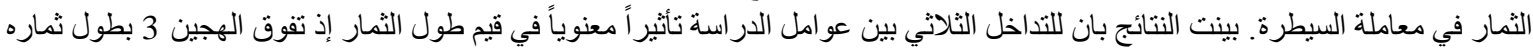
عند التردد 2 أمبير من التيار ومدة التعريض التيض 90 ثانية من الأشعة فأعطى أعلى قيمة لل طول بلغت

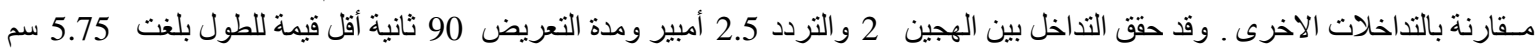

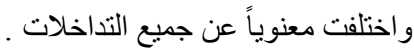
جدول(2): تأثير الهجن وتردد التيار الكهربائي ومدة التعريض للأشعة فوق البنفسجية في طول الثمار (سم ـ ثمرة-1)

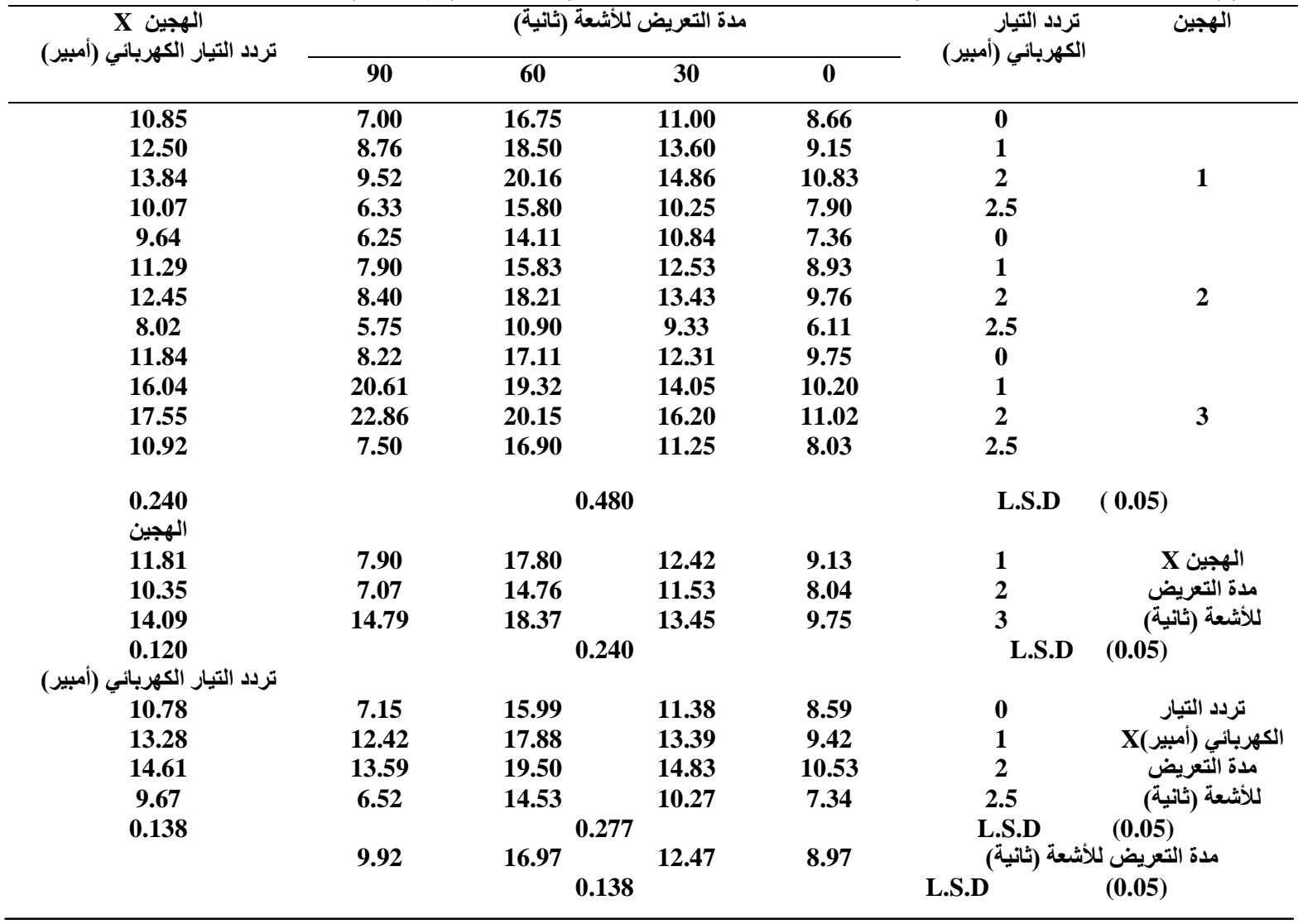




$$
\text { • م قطر الثمار(سم ـ ثمرة-1) }
$$

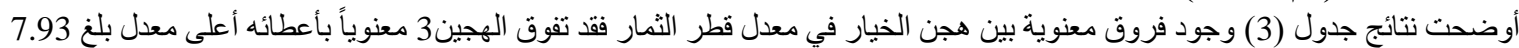

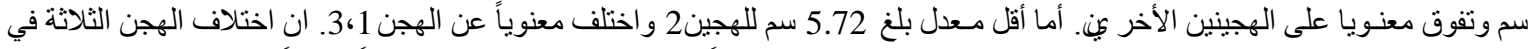

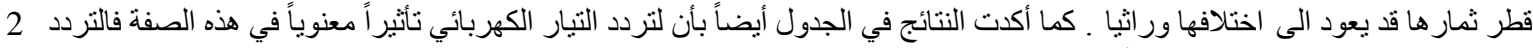

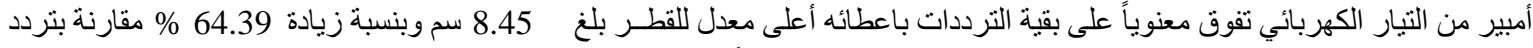

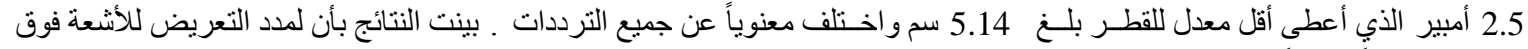

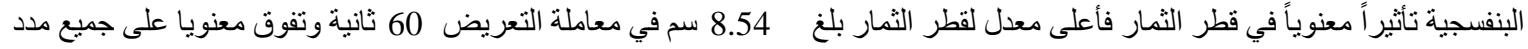

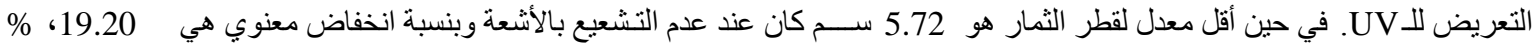

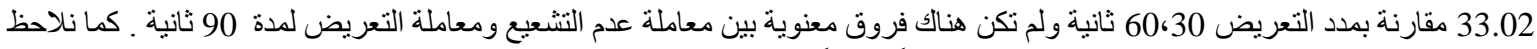

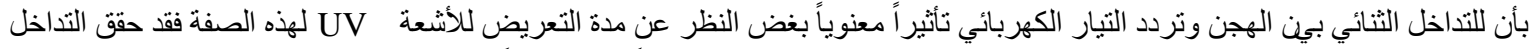

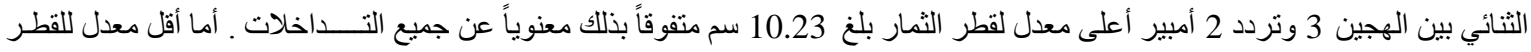

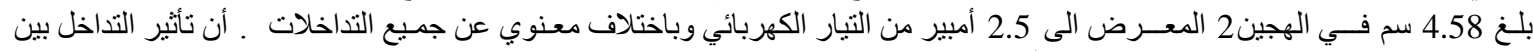

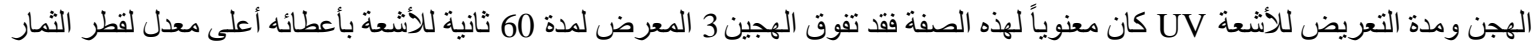

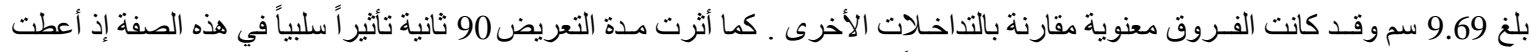

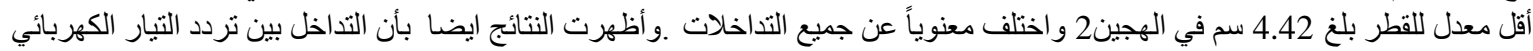

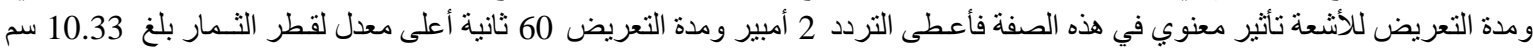

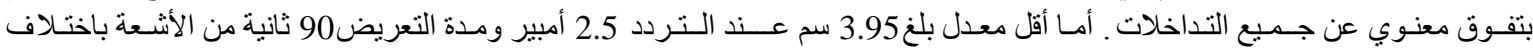

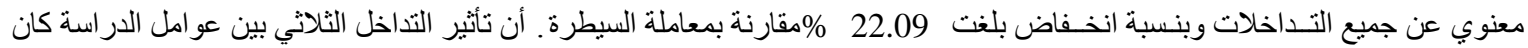

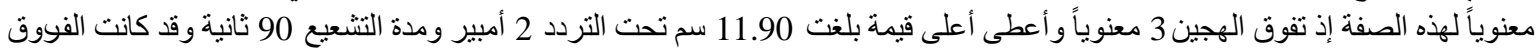

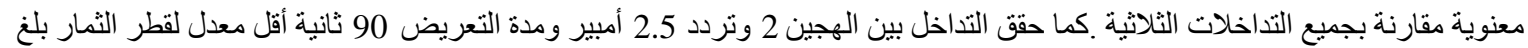

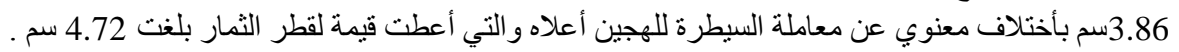
جدول (3): تأثيرالهجن وتردد التيار الكهربائي ومدة التعريض للأشعة فوق البنفسجية في قطر الثمار (سم ـ ثمرة-1)

\begin{tabular}{|c|c|c|c|c|c|c|}
\hline \multirow{2}{*}{ 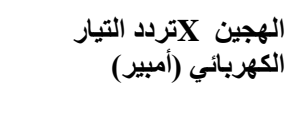 } & \multicolumn{4}{|c|}{ مدة التعريض للأشعة (ثانية) } & \multirow{2}{*}{ ترددالتيار أمبير) } & \multirow[t]{2}{*}{ الهجين } \\
\hline & 90 & 60 & 30 & $\mathbf{0}$ & & \\
\hline 6.23 & 4.62 & 8.79 & 6.53 & 5.00 & 0 & \\
\hline 7.26 & 5.72 & 9.63 & 7.51 & 6.20 & 1 & \\
\hline 8.10 & 6.01 & 10.72 & 8.35 & 7.32 & 2 & 1 \\
\hline 5.05 & 3.98 & 6.16 & 5.73 & 4.33 & 2.5 & \\
\hline 5.10 & 4.04 & 6.13 & 5.53 & 4.72 & 0 & \\
\hline 6.19 & 4.78 & 7.85 & 6.63 & 5.50 & 1 & \\
\hline 7.03 & 5.00 & 8.83 & 7.96 & 6.33 & 2 & 2 \\
\hline 4.58 & 3.86 & 5.64 & 4.83 & 4.01 & 2.5 & \\
\hline 6.82 & 4.75 & 9.68 & 7.36 & 5.50 & $\mathbf{0}$ & \\
\hline 8.89 & 10.30 & 9.91 & 8.44 & 6.93 & 1 & \\
\hline 10.23 & 11.90 & 11.44 & 9.67 & 7.93 & 2 & 3 \\
\hline 5.79 & 4.03 & 7.73 & 6.50 & 4.92 & 2.5 & \\
\hline 0.262 & & & & 0.524 & & S.D $(0.05)$ \\
\hline \multicolumn{7}{|l|}{ الهجين } \\
\hline 6.66 & 5.08 & 8.82 & 7.03 & 5.71 & 1 & الهجين X \\
\hline 5.72 & 4.42 & 7.11 & 6.23 & 5.14 & 2 & مدة التعريض \\
\hline 7.93 & 7.74 & 9.69 & 7.99 & 6.32 & 3 & للأشعة (ثَانيةً) \\
\hline $\mathbf{0 . 1 3 1}$ & & & & 0.262 & & L.S.D $(0.05)$ \\
\hline \multicolumn{7}{|l|}{ تردد التيارالكهربائي (أمبير) } \\
\hline 6.05 & 4.47 & 8.20 & 6.47 & 5.07 & $\mathbf{0}$ & تردد التيار الكهربائي (أمبير) \\
\hline 7.45 & 6.93 & 9.13 & 7.52 & 6.21 & 1 & مدة التعريض XX \\
\hline 8.45 & 7.63 & 10.33 & 8.66 & 7.19 & 2 & للأشعة (ثانية) \\
\hline 5.14 & 3.95 & 6.51 & 5.68 & 4.42 & 2.5 & \\
\hline \multirow[t]{2}{*}{0.151} & & & & $\mathbf{0 . 3 0 3}$ & & L.S.D $\quad(0.05)$ \\
\hline & 5.74 & $\begin{array}{l}8.54 \\
0.151\end{array}$ & 7.08 & 5.72 & .S.D & مدة التعريض للأشعة (ثانية) \\
\hline
\end{tabular}

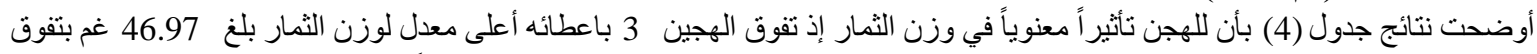

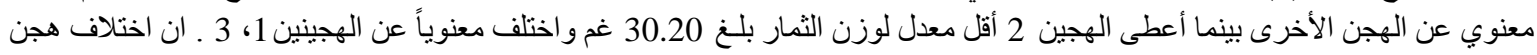

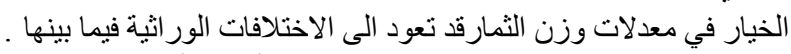

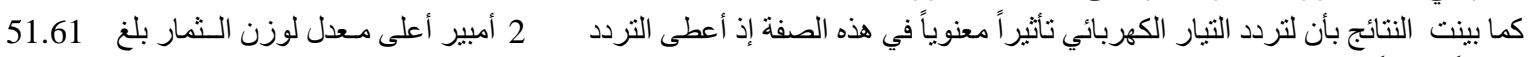

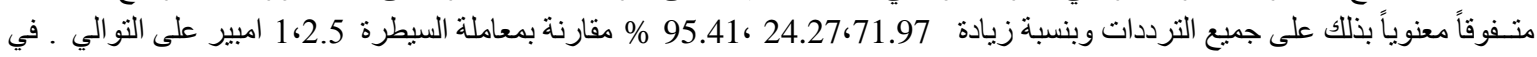




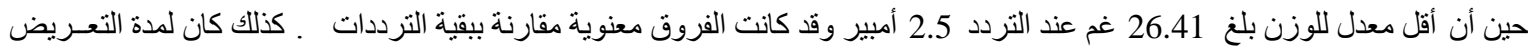

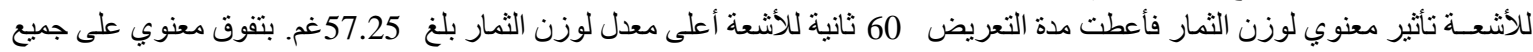

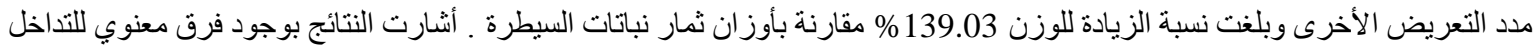

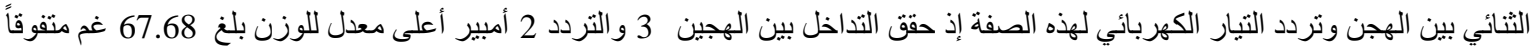

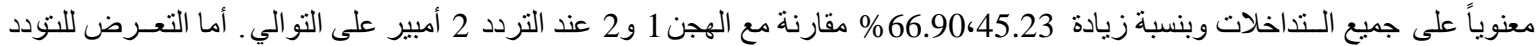

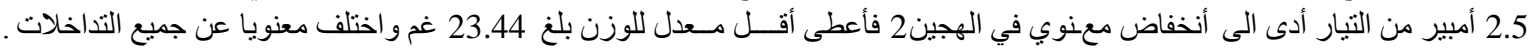

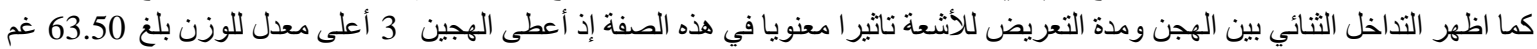

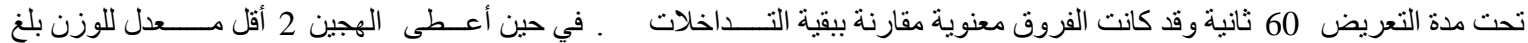

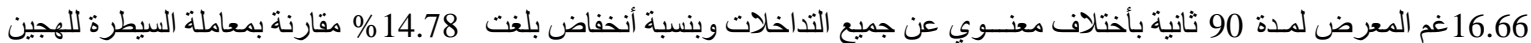

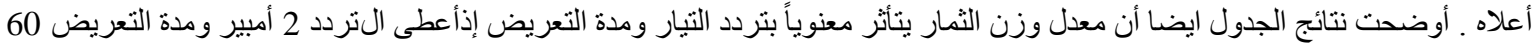

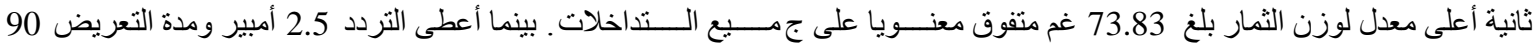

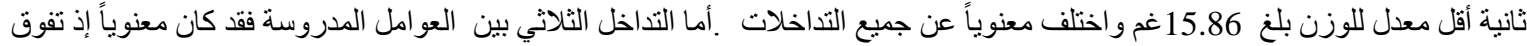

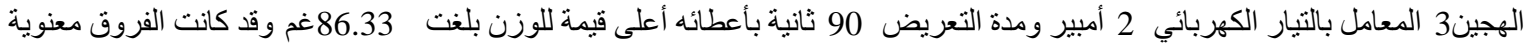

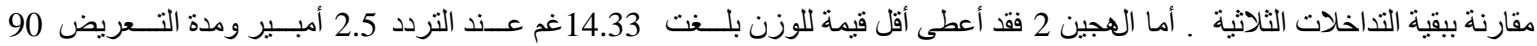

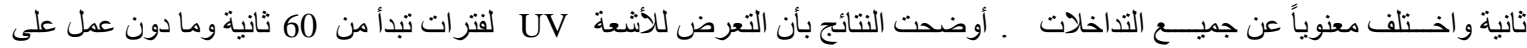

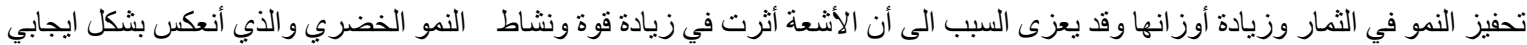

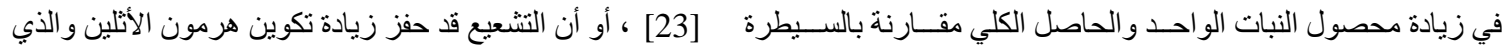

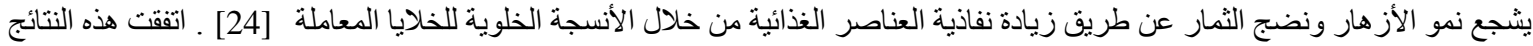

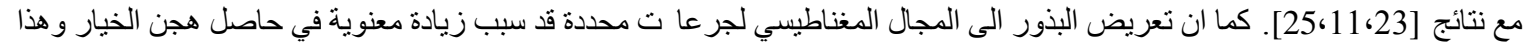

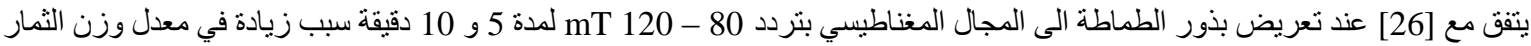

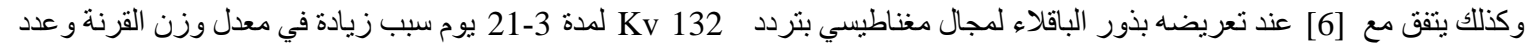

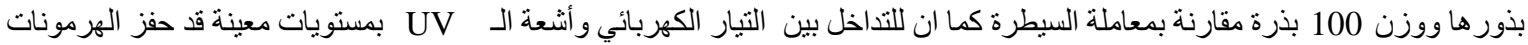

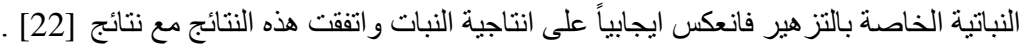

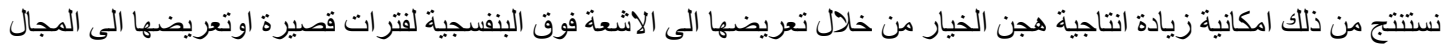

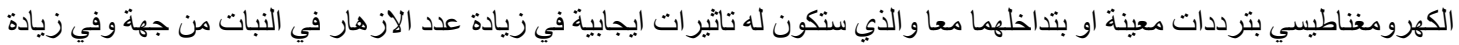

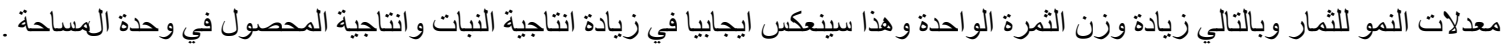

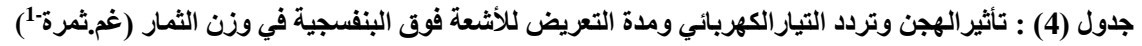

\begin{tabular}{|c|c|c|c|c|c|c|}
\hline \multirow[t]{2}{*}{ الهجين Xتردد التيار الكهربائي (أمبير) } & \multicolumn{4}{|c|}{ مدة التعريض للأشعة (ثانية) } & الكرد التياري امثر & \multirow{2}{*}{ الهجين } \\
\hline & 90 & 60 & 30 & $\mathbf{0}$ & الكهربائي امبير & \\
\hline 31.09 & 17.60 & 52.83 & 35.50 & 18.44 & $\mathbf{0}$ & \\
\hline 37.15 & 18.76 & 60.46 & 48.76 & 20.62 & 1 & 1 \\
\hline 46.60 & 21.91 & 77.73 & 54.51 & 32.26 & 2 & \\
\hline 25.18 & 15.62 & 40.70 & 27.62 & 16.79 & 2.5 & \\
\hline 25.37 & 15.54 & 41.43 & 27.94 & 16.57 & $\mathbf{0}$ & \\
\hline 31.44 & 17.20 & 56.01 & 32.97 & 19.58 & 1 & 2 \\
\hline 40.55 & 19.60 & 65.47 & 50.51 & 26.64 & 2 & \\
\hline 23.44 & 14.33 & 38.43 & 25.57 & 15.43 & 2.5 & \\
\hline 33.57 & 18.30 & 53.60 & 41.71 & 20.69 & $\mathbf{0}$ & \\
\hline 56.00 & 67.24 & 66.98 & 51.36 & 38.43 & 1 & 3 \\
\hline 67.68 & 86.33 & 78.43 & 63.21 & 42.76 & 2 & \\
\hline 30.63 & 17.63 & 55.01 & 30.68 & 19.22 & 2.5 & \\
\hline 0.538 & \multicolumn{4}{|c|}{1.076} & \multirow{2}{*}{\multicolumn{2}{|c|}{ ( 0.05) L.S.D }} \\
\hline الهجين & & & & & & \\
\hline 35.00 & 18.47 & 57.93 & 41.59 & 22.02 & 1 & 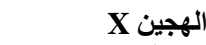 \\
\hline 30.20 & 16.66 & 50.33 & 34.24 & 19.55 & 2 & مدة التعريض ل مد مد \\
\hline 46.97 & 47.37 & 63.50 & 46.74 & 30.27 & 3 & لملأشعة (ثانية) \\
\hline 0.269 & & & & 0.538 & L.S.D & $(0.05)$ \\
\hline \multicolumn{7}{|l|}{ تردد التيار الكهريائي امبير } \\
\hline 30.01 & 17.14 & 49.28 & 35.05 & 18.56 & \multicolumn{2}{|r|}{ تردد التيار الكهربائي } \\
\hline 41.53 & 34.40 & 61.15 & 44.36 & 26.21 & \multirow{2}{*}{\multicolumn{2}{|c|}{ X }} \\
\hline 51.61 & 42.61 & 73.83 & 56.07 & 33.88 & & \\
\hline 26.41 & 15.86 & 44.71 & 27.95 & 17.14 & \multicolumn{2}{|r|}{ للأشعة (ثانية) } \\
\hline \multirow[t]{3}{*}{0.310} & & & & 0.621 & \multirow{2}{*}{\multicolumn{2}{|c|}{ مدة التتريض للاششعة ثانية }} \\
\hline & 27.50 & 57.25 & 40.86 & 23.95 & & \\
\hline & & & & 0.310 & L.S.D & $(0.05)$ \\
\hline
\end{tabular}




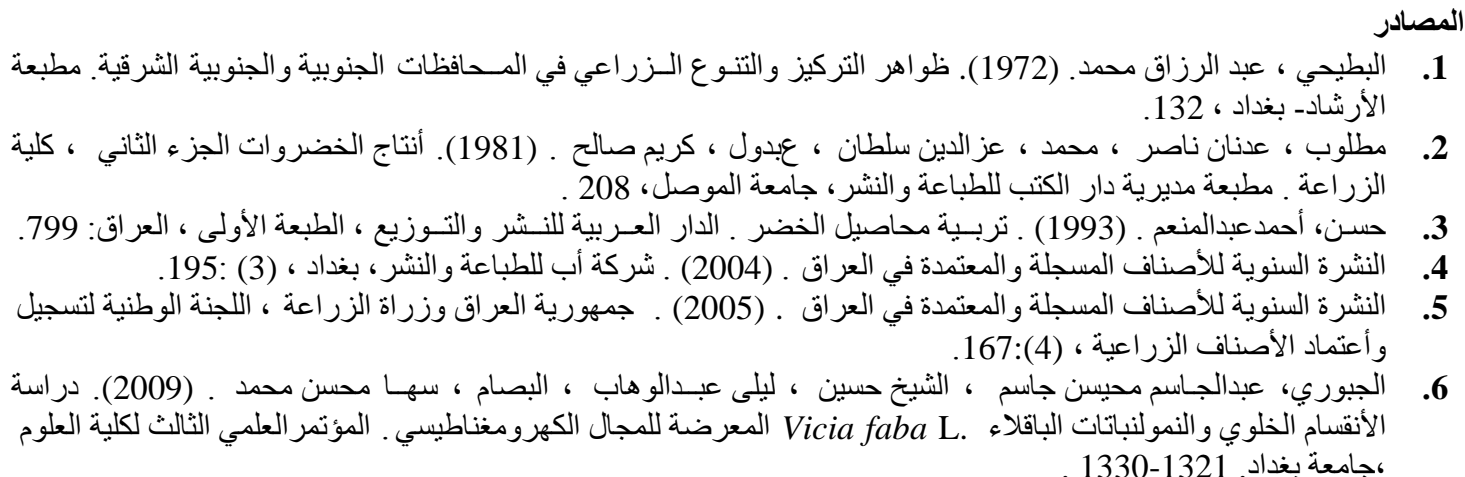

7. Kiatgamjorn,W., Khannger,N. and Nitta, A. (2002).The effect of electric field on Bean sprout growing. ICEMC/Bangkok. 461-467.

8. Lerin, M. and Ernest, S.G. (1995). Applied AC and DC magnetic fields cause some alterations in the mitotic cycle of early Sea urchin embryos. J. Bioelectric magnetic. 16(3):231-240.

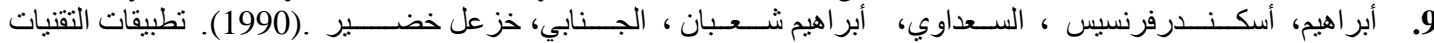

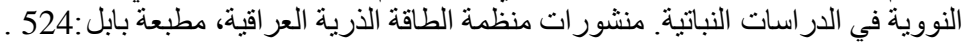
10. سيد ، مرحوم. (2005). الأشعة فوق البنفسجية. مجلة شبكة العر اق الثقافية ، بغداد:

11. Galdwell, C.R. (1993). Induced photo degradation of Cucumber (Cucumis sativus L.) Microsonal and soluble protein Tryptophan Residues in vitro.J. Plant Physiol. 101:947-953.

12. Staselisa, A., Duchorskis, P. and Brazaitytea, A. (2004). Impact of electromagnetic fields on morphogenesis and physiological indices of tomato. J. Int. grophys. 18(3):277-283.

13. Tican, L.R., Aurori, C.M. and Morariu, U.V. (2005). Influence of near null ma- genetic field on in vitro growth of potato and wild Solanum Species. publ.Wiley-Liss,Inc. 26:548-557.

14. Yacili, O. and Alikamanoǵlu, S. (2005).The effect of magnetic field on Paulownia tissue cultures. J. Plant Cell Tissue and Organ Cultur. 83:109-114p.

15. Yao,Y.,Yuan, L., Yang, Y.and chunyang, L. (2005). Effect of seed pretreatment by magnetic field the sensitivity of cucumber(cucumis sativus L.) seedling to ultraviolet-B radiation. Environmental and Experimental Botany. 54:286-294.

16. Ryan, M.Q. (2004). Electromagnetic field and onions; How was tip growth affected proj.sum.California State Science Fair.

17. Davey,R., Bernard, J., Mulligan, B. and John, B.P. (1988). Electro oration In- creases DNA synthesis in cultured plant protoplast. J. Biotechnolo. 6:1091-1093.

18. فر انسيس، وستـن سيزر . (1987). الكهربائية والمغنــطيسية، ترجمة عبد الرسول أحمد درويش، قسم الفيزياء، كلية التربية جامعة البصرة العراق.

19. Sonntag, C.V. (1992).Ultra violet Radation.1-18. http://en.wikipedia.org/wiki/ultraviolet 20.

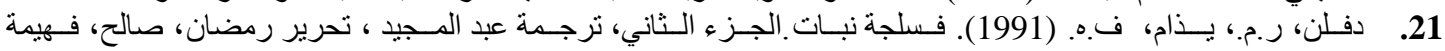

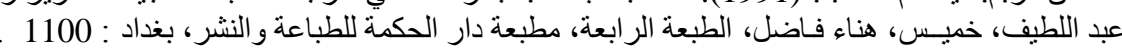

22. Hashimato, I. (2000).Ultraviolet and cucumber fruit. J. of Physic and Chemistry of Soil. 83:652-658.

23. Shinkle, J.R., Edwards, M.C., Koenig, A., Shaltz, A. and Barnes, P.W. (2010). Ph -otomorphogenic regulation of increase in UV-absorbing pigments in cucumber (Cucumis sativus L.)and Arabidopsis thaliana L. seedlings induced by different UV-B andUV-Cwave bands. J. Physiol. Plant.138:113-121. 24. خليفة، محمد ميلود. (1997). مقدمة مختصرة في بايولوجيا النبات. مطبعة معهدالأماء العربي، بيروت، لبنان الطبعة الأولى . .405 25. وليد، عبد اللطيف سامي. (1993). أستخدام منظمات النمو الفيزيائية والكيميائية في أنتاج البطاطا 2 ــ التأثير على نمو النبات

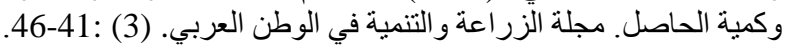

26. Souza, A.D., and Garcia, D. (2005). Pre-sowing magnetic treatment of tomato seeds: effects on the growth and yield of plant cultivated late in the season. Spanish J. of Agricultural Research. 3(1):113122. 